9. Esterhuizen. A. C.. Spriggs, T. L., and Tever, J. D.: Nature of islet-cell innervation in the cat pancreas. Diabetes, 17: 33, (1968).

10. Felig. P.. Wahren, J.. Hendler, R., and Ahlborg, G.: Plasma glucagon levels in exercising man. N. Engl. J. Med., 287: 184 (1972).

11. Gerich, J. E., Karam, J. H., and Forsham, P. H.: Reciprocal adrenergic control of pancreatic alpha and beta-cell function in man. Diabetes, 21: 332 (1972).

12. Gerich. J. E.. Karam. J. H., and Forsham, P. H.: Stimulation of glucagon secretion by epinephrine in man. J. Clin. Endocrinol. Metab.. 37: 479 (1973).

13. Gerich, J. E., Langlois, M., Noacco, C., Schneider, V., and Forsham, P. H.: Adrenergic modulation of pancreatic glucagon secretion in man. J. Clin. Invest., 53: 1441 (1973)

14. Gerich, J. E., Schneider, V. S., Dippe, S., Gustafson, G. M., Karmam, J. H., and Forsham, P. H.: Adrenergic modification of glucagon and insulin responses to arginine in man [Abstract]. Clin. Res., 21: 273 (1973).

15. Hansen. H. P., and Mogensen, C. E.: Growth hormone secretion and kidney function during normalization of the metabolic state in newly diagnosed juvenile diabetics. Hormone Metab. Res., 4: 11 (1972).

16. Harvey, W. D., Faloona, G. R., and Unger, R. H.: The effect of adrenergic blockade on exercise-induced hyperglucagonemia. Endocrinology, 94: 1254 (1974).

17. Imura, H., Kata, Y., Ikeda, M., Morimoto, M., and Yawata, M.: Effect of adrenergic-blocking or stimulating agents on plasma growth hormone, immuno-reactive insulin, and blood free fatty acid levels in man. J. Clin. Invest., 50: 1069 (1971).

18. Iversen, J.: Adrenergic receptors and the secretion of glucagon and insulin from the isolated perfused canine pancreas. J. Clin. Invest., 52: 2102 (1973).

19. Lawrence, A. M., Hagen, T. C., and Kirsteins, L.: Glucagon and growth hormone in ketosis-prone diabetes mellitus. Clin Res., 21: 846 (1973).

20. Lindsay, C. A., and Faloona, G. R.: Adrenergic blockade in shock-induced hyperglucagonemia. Diabetes, 22: 301 (1973).

21. Lippe, B., Sperling, M. and Dooley, R.: Pancreatic alpha and beta cell function in children with cystic fibrosis [Abstract]. Pediat. Res., 8: 435 (1974).

22. Loubatieres, A., Mariani, M. N., Sorez, G., and Savi, L.: The action of beta adrenergic blocking and stimulating agents on insulin secretion: characterization of the type of beta receptor. Diabetologia, 7: 127 (1971).

23. Luyckx, A. S., and Lefebvre, P. H.: Mechanisms involved in the exercise-induced increase in glucagon secretion in rats. Diabetes, 23: 81 (1974).

24. Marks, V.: An improved glucose oxidase method for determining blood, CSF, and urine glucose levels: Clin. Chem. Acta, 4: 395 (1959).
25. Marliss, E. B., Girardier, L., Seydoux, J., Wollheim, C. B., Kanazawa, Y., Orci, L., Renold, A. E., and Porte, D.: Glucagon release induced by pancreatic nerve stimulation in the dog. J. Clin. Invest., 52: 1246 (1973).

26. Martin. J. B.: Neural regulation of growth hormone secretion. N. Engl. J. Med., 288- 1384 (1973).

27. Odell, W. D., Rayford, P. L., and Ross, G. T.: Simplified, partially automated method for radioimmunoassay of human thyroid stimulating. growth, luteinizing and follicle stimulating hormones. J. Lab. Clin. Med., 70: 973 (1967).

28. Porte, D., Jr.: A receptor mechanism for the inhibition of insulin release by epinephrine: J. Clin. Invest., 46: 86 (1967).

29. Porte, D., Jr., and Robertson, R. P.: Control of insulin secretion by catecholamines, stress, and the sympathetic nervous system. Fed. Proc 32: 1792 (1973).

30. Rocha, D. M., Santeusanio, F., Faloona, G. R., and Unger, R. H.: Abnormal pancreatic alpha-cell function in bacterial infections. N. Engl. J. Med., 288: $700(1973)$.

31. Sperling, M. A., DeLamater, P. V., Kazenelson, M., Fiser, R. H., Jr., and Fisher, D. A.: Development and application of a radioimmunoassay for plasma glucagon. Clin. Chem., 20: 566 (1974).

32. Sperling, M. A., Wollesen, F., and DeLamater, P. V.: Daily production and metabolic clearance of growth hormone in juvenile diabetes mellitus. Diabetologia, 9: 380 (1973).

33. Unger, R. H.: Alpha- and beta-cell interrelations in health and disease. Metabolism, 23: 581 (1974).

34. Unger, R. H., Aguilar-Parada, Muller, W. A., and Eisentraut, A. M.: Studies of pancreatic alpha cell function in normal and diabetic subjects. J. Clin. Invest., 49: 837 (1970).

35. Walter, R. M., Dudl, R. H., Palmer, J. P., and Ensinck, J.W.: The effect of adrenergic blockade on the glucagon responses to starvation and hypoglycemia in man. J. Clin. Invest., 54: 1214 (1974).

36. Woods, S. C., and Prote, D., Jr.: Neural control of the endocrine pancreas. Physiol. Rev. 54: 596 (1974).

37. Dr. M. A. Sperling is a recipient of a Research Career Development Award from the United States Public Health Service (1 KO4 HD0029).

38. This research was supported by United States Public Health Service Grants Nos. HD-07087 and RR-425.

39. Requests for reprints should be addressed to: M. A. Sperling, M.B., FRACP., Harbor General Hospital, B-5, 1000 W. Carson St., Torrance, Calif. 90509 (USA).

40. Accepted for publication May 19, 1975.
Brain

cortisol, hydrocortisone

developmental biochemistry fatty acid biosynthesis lung surfactant

\title{
The Influence of Cortisol on the Enzymes of Fatty Acid Synthesis in Developing Mammalian Lung and Brain
}

\author{
IAN GROSS, ${ }^{31}$ SEAMUS A. ROONEY, AND JOSEPH B. WARSHAW \\ Division of Perinatal Medicine, Departments of Pediatrics and Obstetrics and Gynecology, and Lung Research \\ Center, Yale University School of Medicine, New Haven, Connecticut, USA
}

\section{Extract}

Administration of cortisol to fetal rabbits resulted in a $42 \%$ inhibition of pulmonary de novo fatty acid synthesis from acetyl coenzyme A $(\mathrm{CoA})(P=<0.025)$. This was associated with inhibition of acetyl-Co A carboxylase (EC. 6.4.1.2) activity $(P=$ $<0.01)$ and a tendency towards decreased activity of fatty acid synthetase. There was no effect on pulmonary microsomal fatty acid elongation activity. Light and electron microscopic examination of the apex of the right lung of control and cortisol-treated animals revealed changes consistent with accelerated lung maturation in the treated animals.
The in vitro activities of acetyl-Co A carboxylase and fatty acid synthetase were similar in rabbit lung and thus acetyl-Co $\mathrm{A}$ carboxylase activity does not appear to be rate limiting for de novo fatty acid synthesis in lung.

No significant change in the activity of enzymes associated with de novo fatty acid synthesis or microsomal fatty acid elongation was found in fetal brain after cortisol exposure. However, in a parallel study on fatty acid synthesis in fetal liver, cortisol administration resulted in a $\mathbf{3 0} \%$ increase in fatty acid synthetase activity $(P=<\mathbf{0 . 0 2 5})$.

The finding of cortisol-induced inhibition of de novo fatty 
acid synthesis in fetal rabbit lung may be related to the known inhibitory effect of cortisol on lung growth in the fetus.

\section{Speculation}

The antenatal administration of cortisol, in an attempt to prevent hyaline membrane disease, may be accompanied by a number of inhibitory and possibly deleterious effects on cellular metabolism and growth.

Long chain fatty acids are important components of developing lung and brain. In the lung they are found in cell membranes and in the surface-active lipids that maintain alveolar stability. In brain they are found in the complex lipids of the myelin sheath and in the membranes of neurones and glial cells.

Recent studies have revealed both beneficial and deleterious effects after prenatal cortisol administration. Cortisol accelerates the production of pulmonary surfactant (13), and appears to decrease the incidence of hyaline membrane disease in prematurely born infants (16). However, this acceleration of maturation is associated with inhibition of growth. Carson et al. (3) have shown that there is reduction in cell number in the lungs of cortisol-treated fetal rabbits. This effect is reversible with age (15). In the case of the newborn rat brain, however, the reduction in cell number induced by cortisol appears to be permanent $(10)$ and is accompanied by interference with myelination, synaptic growth, and locomotor ability (22).

Because of the importance of long chain fatty acids in developing lung and brain, we have investigated the influence of cortisol on the enzymes of de novo fatty acid synthesis and microsomal fatty acid elongation in these organs in the fetal rabbit. Parallel studies were also performed on fetal rabbit liver.

\section{MATERIALS AND METHODS}

Timed pregnant rabbits were obtained from Camm Research Institute (26) and two to four pregnant does were used for each experiment. On day 24 (gestation in the rabbit is 31 days), the doe was anesthetized with halothane. The uterus was exposed by a midline incision and $1.0 \mathrm{mg}$ hydrocortisone sodium succinate (27) in $0.1 \mathrm{ml}$ saline was injected into the body of each fetus in the left horn. Another $1.0 \mathrm{mg}$ was injected into each amniotic sac in the left horn. An equal volume of sterile $0.9 \%$ saline was then injected into each fetus in the right horn. These saline-injected fetuses served as controls and were marked by a silk suture which was inserted into the superficial layers of the uterine wall over each fetus. The abdominal wall was then closed.

On day 27, $72 \mathrm{hr}$ after injection of cortisol, the does were again anesthetized and the fetuses removed, weighed, and killed by decapitation. The organs from cortisol-treated fetuses were pooled as were those from controls. A total of 12-16 control and treated fetuses were used in each experiment.

The excised organs were chilled in $0.01 \mathrm{M}$ Tris- $\mathrm{Cl}$ buffer, $\mathrm{pH}$ 7.4 , containing $0.001 \mathrm{M}$ EDTA and $0.25 \mathrm{M}$ sucrose. After washing and mincing, the tissue was suspended in 4 volumes of buffer and homogenized for $20 \mathrm{sec}$ in a Brinkmann PT 10 mechanical homogenizer at rheostat setting 2 .

The lung, liver, and brain homogenates were separated into microsomal and supernatant fractions by differential centrifugation as described previously (8). Protein determination was done by a modification of the biuret method (11).

De novo fatty acid synthesis from acetyl-CoA by the supernatant fraction was assayed by measuring the rate of incorporation of acetyl- $\left[1-{ }^{14} \mathrm{C}\right] \mathrm{CoA}$ into pentane-extractable fatty acid as described previously (8). Fatty acid synthetase and microsomal fatty acid elongation activity were assayed by measuring the rate of incorporation of malonyl $\left[2-{ }^{14} \mathrm{C}\right] \mathrm{CoA}$ into pentane-extractable fatty acid (8). Acetyl-CoA carboxylase activity was assayed by measuring the rate of $\mathrm{HCO}_{3}$ incorporation in the presence of acetyl-CoA by a partially purified gel-filtered supernatant fraction as described previously (9).

\section{MICROSCOPY}

In order to confirm that steroid administration was in fact resulting in accelerated lung maturation, the apex of the right lung of control and treated fetuses was examined by light and electron microscopy as described by Kikkawa et al. (12).

\section{RESULTS}

\section{LUNG}

As is shown in Table 1, administration of cortisol to fetal rabbits resulted in a $42 \%$ decrease in fatty acid synthesis from acetyl-coA $(P=<0.025$, paired $t$-test). This inhibition of de novo fatty acid synthesis was associated with an $18 \%$ inhibition of acetyl-CoA carboxylase activity and $23 \%$ inhibition of fatty acid synthetase activity. Although the inhibition of acetyl-CoA carboxylase activity was relatively small, it was statistically significant $(P=<0.01$,

Table 1. Influence of cortisol administration on fatty acid synthesis in fetal lung, liver, and brain ${ }^{1}$

\begin{tabular}{|c|c|c|c|c|c|}
\hline Organ and enzyme system & $\begin{array}{c}\text { No. } \\
\text { experiments }\end{array}$ & Control & Steroid & $\begin{array}{l}\text { Mean of steroid; } \\
\text { control ratios }\end{array}$ & $P$ \\
\hline \multicolumn{6}{|l|}{ Lung } \\
\hline De novo fatty acid synthesis & 4 & $1,188 \pm 222$ & $673 \pm 108$ & $0.58 \pm 0.03$ & $<0.025$ \\
\hline Acetyl-CoA carboxylase & 6 & $1,430 \pm 110$ & $1,170 \pm 110$ & $0.82 \pm 0.05$ & $<0.01$ \\
\hline Fatty acid synthetase & 6 & $1,798 \pm 151$ & $1,470 \pm 303$ & $0.77 \pm 0.14$ & NS \\
\hline Microsomal elongation & 4 & $21.3 \pm 2.7$ & $22.0 \pm 2.7$ & $1.05 \pm 0.12$ & NS \\
\hline \multicolumn{6}{|l|}{ Liver } \\
\hline De novo fatty acid synthesis & 4 & $3,648 \pm 618$ & $4,128 \pm 612$ & $1.14 \pm 0.06$ & NS \\
\hline Acetyl-CoA carboxylase & 4 & $5,190 \pm 890$ & $5,150 \pm 810$ & $1.00 \pm 0.04$ & NS \\
\hline Fatty acid synthetase & 6 & $4,363 \pm 838$ & $5,332 \pm 723$ & $1.30 \pm 0.09$ & $<0.05$ \\
\hline Microsomal elongation & 5 & $22.7 \pm 4.2$ & $27.2 \pm 4.2$ & $1.31 \pm 0.20$ & NS \\
\hline \multicolumn{6}{|l|}{ Brain } \\
\hline Acetyl-CoA carboxylase & 4 & $3,280 \pm 330$ & $2,950 \pm 160$ & $0.91 \pm 0.07$ & NS \\
\hline Fatty acid synthetase & 4 & $3,805 \pm 164$ & $3,628 \pm 288$ & $0.95 \pm 0.04$ & NS \\
\hline Microsomal elongation & 3 & $32.5 \pm 3.0$ & $25.5 \pm 5.2$ & $0.95 \pm 0.09$ & NS \\
\hline
\end{tabular}

\footnotetext{
${ }^{1}$ Overall de novo fatty acid synthesis activity expressed as counts per minute per milligram of protein per minute $( \pm \mathrm{SE})$. Other enzyme activities expressed as picomoles of substrate incorporated per milligram of protein per minute $( \pm \mathrm{SE})$. The steroid to control ratio is the mean $\pm \mathrm{SE}$ of the individual ratios of each experiment. Statistical analysis was by paired $t$-test. NS: Not significant.
} 
paired $t$-test). The decrease in synthetase activity was not significant because of a wider scatter of measurements. There was no significant change in microsomal elongation activity.

\section{LIVER}

Cortisol administration to the fetal rabbit resulted in a $30 \%$ increase in fatty acid synthetase activity $(P=<0.025)$. This was associated with a small (14\%) and insignificant increase in overall de novo fatty acid synthesis. There was no change in acetyl-CoA carboxylase activity. Cortisol administration resulted in a tendency towards increased microsomal elongation activity, but this increase was not statistically significant.

\section{BRAIN}

No significant change in the enzymes associated with de novo fatty acid synthesis or microsomal fatty acid elongation in brain was found after cortisol administration.

\section{ANIMAL WEIGHTS}

There was an $11 \%$ reduction in body weight of the cortisoltreated fetuses. This difference was not statistically significant.

\section{RELATIVE ACTIVITIES OF ACETYL-COA CARBOXYLASE AND FATTY ACID SYNTHETASE}

It has been stated previously that acetyl-CoA carboxylase is the rate-limiting step in de novo fatty acid synthesis in liver (7). In this study it was found that the in vitro activities of acetyl-CoA carboxylase and fatty acid synthetase were similar in both fetal rabbit lung and liver. The ratio of carboxylase to synthetase activity in lung was 0.80 and in liver it was 1.19 .

\section{STATISTICAL ANALYSIS}

Organs derived from fetuses from two to four does were pooled for each experiment. Each enzyme assay was then performed in triplicate on this pooled material and a mean value was obtained. The mean values from three to six separate experiments were analyzed by paired $t$-test for differences between the control and hormone-treated groups.

\section{DISCUSSION}

Fatty acids are synthetized by three subcellular fractions. De novo synthesis occurs in the supernatant fraction of the cell in two stages. In the first stage, acetyl-CoA is converted to malonyl-CoA by acetyl-CoA carboxylase (24). Seven molecules of malonyl-CoA then combine on a base of acetyl-coA to form palmitic acid. This reaction is catalyzed by the fatty acid synthetase complex (2). Chain elongation of fatty acids in the microsomal and mitochondrial fractions of the cell involves elongation of preexisting fatty acids by 2 carbon units. In the mitochondrial system, the 2 carbon source is acetyl-CoA (25) and in the microsomal system, the 2 carbons are derived from malonyl-CoA (18).

Previous work (8) has shown that rabbit lung synthesis fatty acids by all three pathways, but that de novo synthesis is the most active. During fetal life, both mitochondrial and microsomal elongation activity is at very low levels. The product of the de novo pathway is palmitic acid, a component of dipalmityl lecithin, which is a major surface-active lipid.

The action of corticosteroids in accelerating the production of fetal lung surfactant has been well documented. It accelerates the appearance of osmiophilic granules in type II pneumocytes (12), and is associated with a reduction in surface tension of excised lung (13). This action may be related to increased production of lecithin. Farrel and Zachman (5) have reported that cortisone induces a $45 \%$ increase in choline phosphotransferase activity in fetal rabbit lung, but this finding was not confirmed in a later study (20).
As is the case in other organs, this acceleration of maturation in the lung appears to be associated with inhibition of growth. Motoyama et al. (17) found that there was a decrease in fetal rabbit lung weight when cortisol was injected directly into the doe. More recently, Carson et al. (3) have reported a decrease in lung weight and in lung cell number in rabbit fetuses injected with cortisol. According to Kotas (15), however, this effect is reversible and there is later catch-up growth.

Our finding of cortisol-induced inhibition of the enzymes of de novo fatty acid synthesis in fetal rabbit lung is another indication that the acceleration of pulmonary maturity by cortisol may be associated with inhibitory effects on cell growth and metabolism. By microscopic examination of the apex of the right lungs we confirmed that lung maturation was in fact accelerated in our cortisol-treated animals. Morphologic changes consistent with the features of accelerated lung maturation described previously (12) were found and included thinner alveolar walls, wider spaces, and increased numbers of lamellar inclusion bodies in type II cells. Since fatty acids are components of growing lung cell membranes, it is possible that this inhibition of fatty acid synthesis is related to inhibition of growth.

The selection of suitable controls for studies of hormonal effect on lung maturation in fetal rabbits poses a number of problems. Operative stress and the stress of injection appear to result in some cortisol-like effect on lung maturation. Russell et al. (21) have shown that injection of saline into fetal rabbits results in significant increase in the incorporation of labeled choline into lecithin, when compared with noninjected, nonoperated controls. Thus any agent to be tested should produce more effect than that of saline injection. We have used saline-injected littermates in the contralateral uterine horn as controls in order to minimize differences due to variations in operative stress and animal to animal biologic variation. Using this model, significant cortisol-induced differences in lung physiology and morphology have been demonstrated previously $(12,16)$, despite the fact that it has been indicated that there may be minimal transfer of injected hormone to the fetuses in the opposite horn (14). Should such a transfer have occurred, the effect would have been to blur, rather than accentuate, the hormonally-induced differences demonstrated.

The fatty acids of pulmonary surfactant may be derived from either exogenous or endogenous sources (6). Conclusive kinetic studies have not been performed to evaluate the relative contributions of pulmonary and nonpulmonary-derived fatty acids to lung lecithin, and thus it is difficult at this stage to attempt to evaluate the possible effect of decreased lung fatty acid synthesis on surfactant production.

There has been some controversy in the literature as to whether acetyl-CoA carboxylase is the rate-limiting step in de novo fatty acid synthesis (4). Since the activities of acetyl-CoA carboxylase and fatty acid synthetase in fetal rabbit lung were similar in our study, it would appear that, in vitro, acetyl-CoA carboxylase is not rate-limiting. The activity of these two enzymes was also similar in liver and thus our data supports the finding of Chang et al. (4), who felt that acetyl-CoA carboxylase was not the rate-limiting step in hepatic de novo fatty acid synthesis.

The influence of cortisol on developing rat brain has been the subject of many recent studies. Schapiro (22) showed that after a single dose of $1.0 \mathrm{mg}$ cortisol to 1-day-old rats, there is a decrease in brain cholesterol, decreased spiny processes on pyramidal cell dendrites, and a diminution in spontaneous exploratory or locomotor activity. Howard (10) has demonstrated that cortisol induces a reduction in brain weight and in total DNA content, particularly in the cerebellum. The reduction in brain cell number is permanent, unlike that in lung. More recently Oda (19) confirmed that cortisol-treated newborn rats have impairment of myelination and decreased synaptic growth and dendritic arborization.

Previous work has shown that the activities of acetyl-CoA carboxylase (9), fatty acid synthetase (23), and microsomal fatty acid elongation (1) are high during the period of rapid brain growth in the rat and then decline with increasing age. Although 
these enzyme activities seem to parallel the rate of brain growth, we could not demonstrate any change in fetal rabbit brain under our conditions of cortisol exposure.

Little information is available from previous studies on the effects of cortisol on the enzymes of fatty acid synthesis. Volpe and Kishimoto (23) showed that a single injection of cortisol produced no change in fatty acid synthetase activity in liver or brain of the newborn rat. If, however, cortisol was given on at least 6 consecutive days, hepatic synthetase activity was reduced by about $50 \%$. No consistent inhibition of brain synthetase activity was produced by administration of cortisol for a longer period. This data is similar to our observation with brain, but contrasts with the stimulation of hepatic fatty acid synthetase activity which we observed after a single cortisol injection into the rabbit fetus.

The finding of cortisol-induced inhibition of pulmonary fatty acid synthesis in this study emphasizes the fact that the acceleration of pulmonary maturity by cortisol is associated with other inhibitory effects on cellular metabolism and growth.

\section{SUMMARY}

The administration of cortisol to fetal rabbits resulted in inhibition of the enzymes of de novo fatty acid synthesis in the lung. Concomitant with this inhibition there was microscopic evidence of enhanced pulmonary maturation. Cortisol administration had no effect on the enzymes of fatty acid synthesis in fetal rabbit brain.

The inhibition of the enzymes of de novo pulmonary fatty acid synthesis by cortisol administration may be related to the known inhibitory effect of cortisol on fetal lung growth.

\section{REFERENCES AND NOTES}

1. Aeberhard, E., Grippo, J., and Menkes, J. H.: Fatty acid synthesis in the developing brain. Pediat. Res., 3: 590 (1969).

2. Bressler, R., and Wakil, S. J.: Studies on the mechanism of fatty acid synthesis IX. The conversion of malonyl coenzyme $\wedge$ to long chain fatty acids. J. Biol. Chem., 236: 1643, (1961).

3. Carson, S. H., Taeusch, H.W., and Avery, M. E.: Inhibition of lung cell division after hydrocortisone injection into fetal rabbits. J. Appl. Physiol., 34: 660, (1973).

4. Chang, H., Seidman, I., Teebor, G., and Lane, M. D.: Liver acetyl-CoA carboxylase and fatty acid synthetase: Relative activities in the normal state and in hereditary obesity. Biochem. Biophys. Res. Commun., 28: 682 (1967)

5. Farrel, P. M., and Zachman, R. D.: Induction of choline phosphotransferase and lecithin synthesis in the fetal lung by corticosteroids. Science, 179: 297 (1973).

6. Felts, J. M.: Biochemistry of the lung. Health Phys., 10: 973 (1964).

7. Ganguly, J.: Studies on the mechanism of fatty acid synthesis. VII. Biosynthesis of fatty acids from malonyl-CoA. Biochem. Biophys. Acta, 40: 110 (1960).
8. Gross, I., and Warshaw, J. B.: Enzyme activities related to fatty acid synthesis in developing mammalian lung. Pediat. Res., 8: 193 (1974).

9. Gross, I., and Warshaw, J. B.: Fatty acid synthesis in developing brain: Acetyl-CoA carboxylase activity. Biol. Neonate, 25: 365 (1974).

10. Howard, E.: Reductions in size and total DNA of cerebrum and cerebellum in adult mice after corticosterone treatment in infancy. Exp. Neurol., 22: 191 (1968).

11. Jacobs, E E., Jacobs, M., Sanadi, D. R., and Bradley, L.: Uncoupling of oxidative phosphorylation by the cadmium ion. J. Biol. Chem., 223: 147 (1956).

12. Kikkawa, Y., Kaibara, M., Motoyama, E. K., Orzalesi, M. M., and Cook, C. D.: Morphological development of the fetal rabbit lung and its acceleration with cortisol. Amer. J. Pathol. 64: 423 (1971)

13. Kotas, R. V., and Avery, M. E.: Accelerated appearance of pulmonary surfactant in the fetal rabbit. J. Appl. Physiol., 30: 358 (1971).

14. Kotas, R. V., Fletcher, B. D., Torday, J., and Avery, M. E.: Evidence for independent regulators of organ maturation in fetal rabbits. Pediatrics, 47:57 (1971)

15. Kotas, R. V., Mims, L. C., and Hart, L. K. Reversible inhibition of lung cell number after glucocorticoid injection into fetal rabbits to enhance surfactant appearance. Pediatrics, 53: 358 (1974).

16. Liggins, G. C., and Howie, R. N.: A controlled trial of antepartum glucocorticoid treatment for prevention of the respiratory distress syndrome in premature infants. Pediatrics, 50: 515 (1972).

17. Motoyama, E. K., Orzalesi, M. M., Kikkawa, Y., Kaibara, M., Wu, B., Zigas, C., and Cook, C. D.: Effect of cortisol on the maturation of fetal rabbit lungs. Pediatrics, 48 : 547 (1971).

18. Nugteren, D. H.: The enzymic chain elongation of fatty acids by rat liver microsomes. Biochim. Biophys. Acta, 106: 280 (1965).

19. Oda, M. S.: The effect of corticosteroids on the morphology of the developing rat brain (M. D. thesis, Yale University School of Medicine, 1974).

20. Rooney, S. A., Gross, I., Motoyama, E. K., and Warshaw, J. B.: Effects of cortisol and thyroxine on fatty acid and phospholipid biosynthesis in fetal rabbit lung: Physiologist, 17: 323 (1974).

21. Russell, B. J., Nugent, L., and Chernick, V. Effects of steroids on the enzymatic pathways of lecithin production in fetal rabbits. Biol. Neonate, 24: 306 (1974).

22. Schapiro, S.: Some physiologic biochemical and behavioral consequences of neonatal hormone administration: Cortisol and thyroxin. Gen. Comp. Endocrinol., 10: 214 (1968).

23. Volpe, J. J., and Kishimoto, Y.: Fatty acid synthetase of brain: Development, influence of nutritional and hormonal factors and comparison with liver enzyme. J. Neurochem., 19: 737 (1972).

24. Waite, M., and Wakil, S. J.: Studies on the mechanism of fatty acid synthesis. XII. Acety1 coenzyme A Carboxylase. J. Biol. Chem., 237: 2750 (1962).

25. Wit-Peters, E. M.: Synthesis of long chain fatty acids in mitochondria. Biochim. Biophys. Acta, 176: 453 (1969)

26. Wayne, N. J.

27. Solucortef, Upjohn Co., Kalamazoo, Mich.

28. The authors wish to thank Dr. E. K. Motoyama for advice and assistance, Dr. L. Gassenheimer for performing the microscopic studies, and Ms. C. Zigas and Mrs. C. Barrett for expert technical assistance.

29. This work was presented in part at the Fall meeting of the American Physiology Society, Albany, Aug. 12-16, 1974.

30. This research was supported by United States Public Health Service Grants nos. HD-8293 and HL-14179 (SCOR) and Connecticut Heart Association Grant no. 536.

31. Requests for reprints should be addressed to: I. Gross, M.D., Department of Pediatrics, 333 Cedar St., New Haven, Conn. 06510 (USA).

32. Accepted for publication June 3, 1975. 